\title{
Review
}

\section{Coupling of mitochondrial translation with the formation of respiratory complexes in yeast mitochondria}

\author{
Agnieszka Chacińska and Magdalena Boguta
}

Institute of Biochemistry and Biophysics, Polish Academy of Sciences,
A. Pawińskiego 5A, 02-106 Warszawa, Poland

Received: 28 August, 2000; revised: 31 October, 2000; accepted: 2 November, 2000

Key words: Saccharomyces cerevisiae, mitochondrial translation, mitochondrial ribosomes, translational activators, mitochondrial inner membrane

\begin{abstract}
In contrast to most other eukaryotic organisms, yeast can survive without respiration. This ability has been exploited to investigate nuclear genes required for expression of mitochondrial DNA. Availability of complete Saccharomyces cerevisiae genomic sequence has provided additional help in detailed molecular analysis. Seven of the eight major products encoded by mitochondrial DNA are hydrophobic subunits of respiratory complexes in the inner membrane. Localization of the translation process in the same cellular compartment ensures synthesis of mitochondrially encoded proteins near sites of their assembly into multimeric respiratory complexes. Association of mitochondrial ribosomes with the membrane is mediated by mRNA-specific translational activators, that are involved in the recognition of initation codon. The newly synthesized mitochondrial proteins are transferred to membrane by a specific export system. This review discusses the role of membrane-localized factors responsible for quality control and turnover of mitochondrially synthesized subunits as well as for assembly of respiratory complexes.
\end{abstract}

Biogenesis of the enzymes of oxidative phosphorylation in eukaryotes is dependent on two genetic systems, mitochondrial and nuclear. Mitochondria have their own genome and the machinery to express the information contained in it. The role of the mitochondrial genetic system is to supply only a few highly hydrophobic proteins of respira- tory complexes embedded in the inner membrane. The majority of the subunits of energy-transducing complexes, as well as proteins involved in mitochondrial genome expression and assembly, are encoded by nuclear genes.

In the yeast Saccharomyces cerevisiae, all components of complex I and complex II are

\footnotetext{
${ }^{-}$This work was supported by the State Committee for Scientific Research (KBN) grant 6PO4B02915 Abbreviations: MRP, mitochondrial ribosomal protein; 5'-UTL, 5'-untranslated leader sequence.
} 
provided by nuclear genome (Fig. 1). Complex III (or ubiquinol-cytochrome $c$ oxidoreductase, or $b c_{1}$ complex) is composed of nine sub- ties and is highly suitable for genetic manipulations. The respiratory function is dispensable as long as cells grow by fermentation.

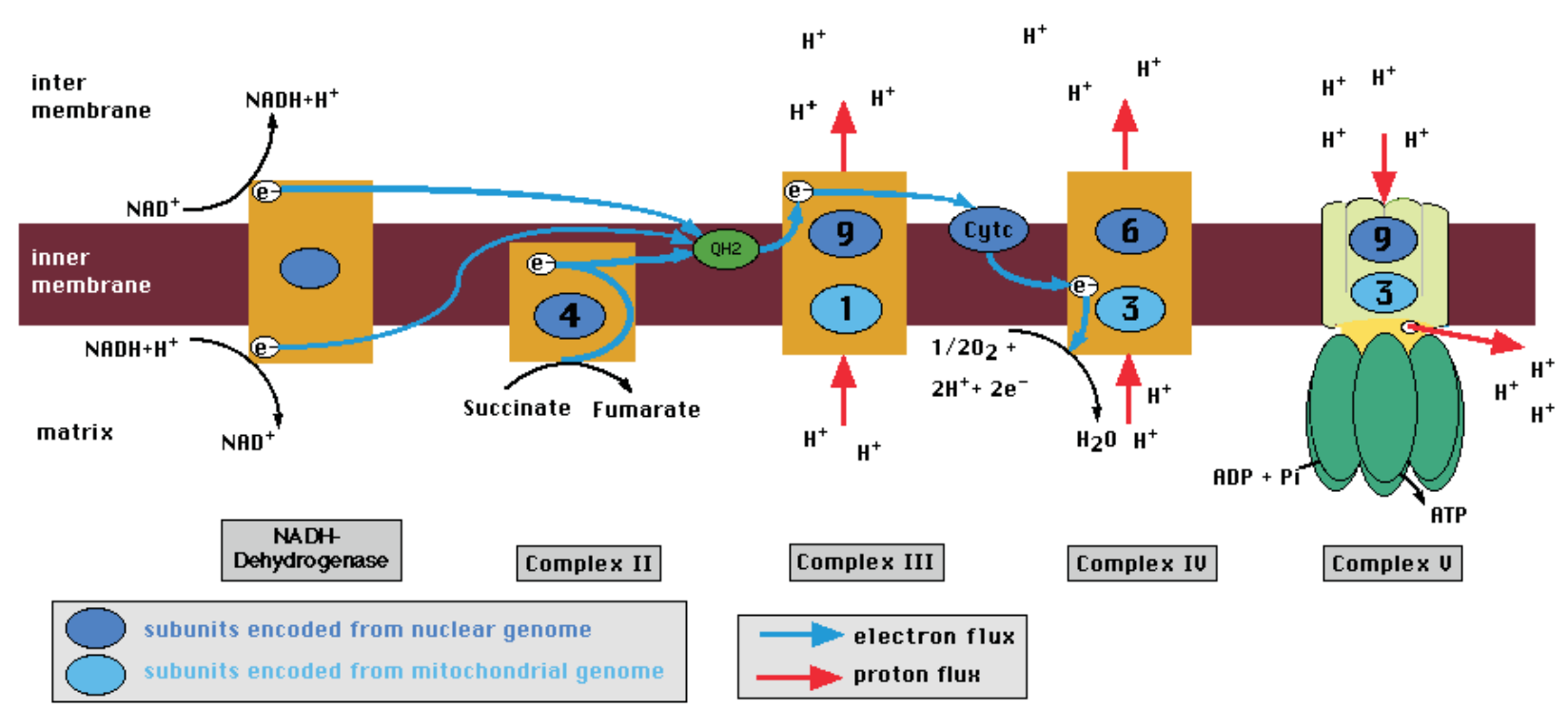

Figure. 1. Schematic representation of the respiratory chain complexes of S. cerevisiae.

From MITOP, database of mitochondria-related genes and proteins. Number of subunits encoded by nucleus and mitochondria is given.

units, but only one among them, cytochrome $b$, is encoded by the mitochondrial gene $C O B$ (Rodel, 1997). Cytochrome $c$ oxidase (or complex IV) contains three mitochondrially synthesized proteins, products of the COX1, COX2 and COX3 genes, in addition to those provided by the nucleus (Poyton et al., 1995). Three proteins encoded by mitochondrial genes ATP6, ATP 8 and ATP9 are components of the integral membrane $\mathrm{F}_{0}$ component of ATP synthase (or complex $\mathrm{V}$ or $\mathrm{F}_{0} \mathrm{~F}_{1}$-ATPase). In contrast, the peripherally bound $\mathrm{F}_{1}$ component consists only of proteins synthesized in the cytosol (Arnold et al., 1999) (Fig. 1).

The yeast $S$. cerevisiae as a facultative anaerobe offers distinct advantages for biochemical and genetic studies of mitochondrial gene expression and respiratory metabolism. Yeast is readily propagated on simple, welldefined media, can be grown in large quanti-
This means that mutations affecting expression or functioning of the respiratory chain lead to the respiratory deficient phenotype but are viable on a fermentable carbon source. The only factor complicating genetic manipulations is that the complete loss of mitochondrial translation causes, for unknown reasons, irreversible instability of mitochondrial DNA leading to deletions ( $r h o^{-}$) or complete lack of mitochondrial DNA $\left(r h o^{0}\right)$ (Myers et $a l .$, 1985). Some aspects of mitochondrial gene expression cannot be studied directly due to the lack of an in vitro protein synthesis system derived from these organelles of any species. However, isolated mitochondria are capable of protein synthesis (McKee \& Poyton, 1984).

This review focuses on the process of mitochondrial translation and its connection with subsequent membrane-specific events leading to the assembly of newly synthesized proteins into functional respiratory complexes. 


\section{MITOCHONDRIAL RIBOSOMES}

Mitochondria contain their own translational machinery and use an alternative genetic code (Hudspeth et al., 1982). Although the mitochondrial translation system shows unique and unusual features, it resembles more closely its prokaryotic than its eukaryotic counterpart with respect to the spectrum of antibiotics inhibiting mitochondrial translation (Borst \& Grivell, 1971).

Mitochondrial ribosomes in yeast have the sedimentation coefficient of $74 \mathrm{~S}$ and they are dissociable into $54 \mathrm{~S}$ and $37 \mathrm{~S}$ subunits. Like in other eukaryotes, their mass ratio of protein to RNA is higher than in Eubacteria. Most mitochondrial ribosomes contain only two RNA species; in yeast $15 \mathrm{~S}$ and $21 \mathrm{~S}$ rRNAs are found. Both are encoded by mitochondrial DNA and display minimal posttranscriptional modifications (Grivell, 1995). Since a large portion of mitochondrial ribosome mass is provided by proteins, it is not surprising that mitochondrial ribosomal proteins (MRPs) exceed those of bacteria in number and very often in length. Mitochondrial ribosomes do not share any constituents with the cytoplasmic ones, although all but one proteins are encoded by the nuclear genome, synthesized on cytoplasmic ribosomes and subsequently imported into the mitochondria. The only MRP encoded by the mitochondrial genome is the Var1p that has been shown to be an essential and stoichiometric component of the small subunit of the mitochondrial ribosome, involved additionally in its assembly (Mason et al., 1996). MRPs were identified by different approaches including sequence analysis, genetic complementation of pleiotropic phenotypes deficient in mitochondrial protein synthesis, immunological screening of expression libraries with antibodies against MRPs or by direct biochemical methods: separation on one dimensional or two-dimensional PAGE, purification and finally amino-acid sequencing. The total number of identified MRPs is 63 (Grivell et al., 1999) and it seems to be not a complete set since 50 proteins of the large and 35 proteins of the small ribosomal subunit have been detected by direct biochemical methods (Graack \& Wittmann-Liebold, 1998). For the majority of MRPs genes, their inactivation leads to instability of mitochondrial DNA. Of the MRPs whose sequences are known, some are homologues of ribosomal proteins from other organisms, others have domains similar to bacterial ribosomal proteins attached to domains with no recognizable homology to known proteins, but the majority are completely unique (Graack \& Wittmann-Liebold, 1998). This relatively low degree of sequence conservation is a surprising feature. It has been speculated that the conserved proteins are responsible for carrying out the central step of protein synthesis, while additional proteins or their parts have more specialized functions connected with the coupling of the translation process to the mitochondrial inner membrane, which is the final destination of 7 hydrophobic mitochondrial translation products (Fox, 1996a).

An example of a protein displaying the features described is Nam9p (Boguta et al., 1992; 1997; Dmochowska et al., 1995; Biswas \& Getz, 1999). The N-terminal domain of Nam9p shows strong homology to a class of S4 ribosomal proteins from prokaryotes and eukaryotes. The phenotype of the nam 9-1 point mutant is a nonsense suppression of [ $\left.\mathrm{mit}^{-}\right]$ochre mutations in different mitochondrial genes. It has been postulated that Nam9p controls the fidelity of mitochondrial translation.

\section{GENERAL FACTORS OF MITOCHONDRIAL TRANSLATION}

Mitochondrial mRNAs are uncapped and lack the poly(A) tail. They contain 5'-untranslated leader sequences ( $5^{\prime}$-UTLs) that vary in size from about 50 up to several hundred nucleotides. Little is known about the translational start site selection. Interactions 
of "Shine-Dalgarno" type between the 3 '-end of $15 \mathrm{~S}$ rRNA and the messenger are unlikely to play a role in this process due to variable distance of the Shine-Dalgarno box from the initiation codon. Indeed, a chimeric mRNA lacking the putative Shine-Dalgarno box was translated normally in vivo (Costanzo \& Fox, 1988). Simple scanning of mRNA by ribosome can be ruled out since $5^{\prime}$-UTLs contain additional upstream AUG codons, short open reading frames and a stable secondary structure (Pel \& Grivell, 1994). Other mechanisms, such as entry at an internal landing site may be rather used to guide the ribosome to the initiation AUG codon, as shown in studies carried out with COX2 and COX3 mRNAs in which the initiator AUG had been mutated to AUA, the alternative methionine codon in yeast mitochondrial DNA. Translation from such mutated mRNAs was strongly impaired leading to a leaky nonrespiratory phenotype (Folley \& Fox, 1994; Mulero \& Fox, 1994). Interestingly, the residual translation in such mutants was initiated at the altered initiation codon, not at the next downstream AUG (Mulero \& Fox, 1994; Bonnefoy \& Fox, 2000). This finding led to the important conclusion that, in addition to AUG, some sequence or structural information must be used for selection of the proper initiation site. Thus, when the initiator AUG is mutated to AUA, the surrounding nucleotides provide sufficient information to select the proper start site, albeit at a low efficiency.

The mechanism of start site selection remains obscure, but it is known that initiation of translation requires mRNA-specific activator proteins whose targets lie in the $5^{\prime}$-UTLs (reviewed by Fox, 1996a). The messenger-specific translational activators may be involved in positioning of the ribosome over the correct AUG initiation codon. The role and features of the mitochondrial translational activation system, which is one of the most unusual mechanisms involved in gene expression, will be discussed in detail in the following section.
Besides specific activators some general components of the protein synthesis machinery are also involved in the initiation of translation. Certain mutations in $5^{\prime}$-UTLs of $\mathrm{COX} 2$ and $C O X 3$ mRNA were suppressed by mutations in genes encoding proteins of the small ribosomal subunit, MRP21 and MRP51. The suppression by ribosomal proteins did not by-pass the mRNA-specific translational activation system and was not due to a general increase in translational efficiency since the mrp21 and mrp51 mutants failed to suppress the leaky non-respiratory phenotype of the COX2 and COX3 initiation codon mutants (Green-Willms et al., 1998). These data indicate that the ribosome plays an active role in the recognition of translation start signals. As the suppression was not gene specific, the mitochondrial ribosome might recognize a common element in $5^{\prime}$-UTLs. A candidate for such an element is the octanucleotide sequence UAUAAAUA that has been identified in COX2 mRNA and found in other 5 '-UTLs (Dunstan et al., 1997). Ribosomal proteins Mrp21 and Mrp51 could be involved in the association of the ribosome with mRNA which additionally requires specific activator proteins, resulting in selection of the proper site for the initiation of translation.

The nuclear gene IFM1 encodes the yeast mitochondrial homologue of prokaryotic initiation factor IF-2. The protein probably functions in mitochondrial translation initiation since mutants display features commonly found in strains defective in mitochondrial protein synthesis (Vambutas et al., 1991), although the connection of Ifm $1 p$ with other elements specifying proper translation initiation has not been demonstrated so far.

The elongation step of mitochondrial translation requires products of two nuclear genes MEF2 and MEF1 that are homologous to prokaryotic elongation factors EF-Tu and EF-G, respectively (Nagata et al., 1983; Vambutas et al., 1991). Both these yeast mitochondrial elongation factors display activity 
in the presence of $E$. coli ribosomes (Rosenthal \& Bodley, 1987).

Frame-shift mutations at a specific run of U residues in the coding sequence of the $\mathrm{COX} 2$ gene that disturb elongation lead to a leaky phenotype (Fox \& Weiss-Brummer, 1980). Interestingly, ribosomal frame-shifting is reduced in the genetic background of the paramomycin resistance mutation in the mitochondrial gene encoding 15S rRNA (Weiss-Brummer \& Huttenhofer, 1989).

Up to date the only protein involved in the termination of mitochondrial translation is Mrf1p. It is homologous to prokaryotic RF1 specific for UAA and UAG and should be sufficient for the recognition of UAA and UAG in mitochondria; UGA is not the stop codon in mitochondrial translation (Pel et al., 1992b). When overproduced, Mrf1p reduced the nonsense suppression caused by two well characterized ribosomal ambiguity mutations: nam9-1 in a gene encoding the mitochondrial ribosomal protein responsible for translation fidelity (Boguta et al., 1992; Dmochowska et al., 1995; Chacinska et al., 2000) and MSU1, in a gene specifying $15 \mathrm{~S}$ rRNA (Pel et al., 1992b; 1993; Fox, 1996a). These data provide strong evidence that Mrf1p is a mitochondrial translation release factor. This antisuppression phenotype is in good agreement with the observation found previously for RF1 in $E$. coli that an increased level of the peptide release factor changes the balance between termination and elongation, reducing readthrough of stop codons (Weiss et al., 1984).

As expected for the proteins generally required for translation, deletion of MRF1 leads to the destabilization of mtDNA. Two known mrf1 missense mutations appear to define the ribosome binding domain in the Mrf1 protein and lead to the non-respiratory phenotype although mtDNA remains intact. Interestingly, both mutations cause defects in Cox $2 p$ synthesis and in the splicing and/or translation of COX1 mRNA, which is not in agreement with expectations based on studies of other mutant general translational factors, ifm 1 and mef1, displaying an overall reduction in mitochondrial protein synthesis (Vambutas et al., 1991; Pel et al., 1992a; 1992b; 1993). The non-respiratory phenotype of mrf1 mutants on the background of intron-less mitochondrial DNA allowed the authors to hypothesize that the splicing impairment is a secondary effect of the lack of intact maturases due to the disturbances in mitochondrial protein synthesis. The molecular basis of this specific translational phenomenon in mrf1 mutants remains unknown.

Another protein involved in mitochondrial translation, the product of the PET112 gene, probably performs a general function, since the null mutation destabilizes mitochondrial DNA. Interestingly, a point mutation in this gene specifically blocks the synthesis of Cox $2 p$, which resembles the effect of $m r f 1 \mathrm{mu}-$ tations (Mulero et al., 1994).

Two other mitochondrial proteins, Mss1p and Mto1p, that form a complex seem to control translation. Both genes were cloned by complementation of mutations that result in a non-respiratory phenotype only in the presence of a point mutation in mitochondrial 15S rRNA conferring resistance to paramomycin (par $^{\mathrm{R} 454}$ ) (Decoster et al., 1993; Colby et al., 1998). Both proteins were dispensable for respiratory growth in the genetic background of wild type mtDNA. In the paramomycin-resistant background the $m s s 1$ and $m$ to 1 mutations partially blocked the splicing of COX1 mRNA and caused a complete absence of Cox $1 p$, although synthesis of other mitochondrial translation products was increased. The widespread occurrence of homologous proteins in prokaryotes argues for the general role of the Mto1p/Mss1p complex in the process of translation. Probably the Mto1p/Mss1p complex has a proof-reading function slowing down the rate of translation, and perhaps interacts transiently, since no stable association could be detected, with the small subunit of the ribosome. In the presence of the paramomycin-resistance mutation this interaction is weakened or prevented, resulting in a high rate of 
amino-acid substitutions in mitochondrially translated proteins. Therefore a large part of translation products cannot be functional, possibly including intron-encoded maturases involved in the processing of COX1 mRNA. The complete lack of the Cox 1 subunit could be explained by its more rapid turn-over. Thus, in addition to the increase in translation rate of each product, the rate of degradation may account for the pattern of mitochondrially synthesized proteins in the mutant Mto1p/Mss1p (Decoster et al., 1993; Colby et al., 1998).

\section{TRANSLATIONAL ACTIVATION}

The requirement for gene-specific activator proteins for translation of most, if not all, mRNAs is the unusual feature of the mitochondrial expression system. To date the translation of five of the seven major mitochondrially encoded membrane proteins has been shown to depend on specific nuclear genes. Mutants defective in either of these genes showed the respiratory defective phenotype due to the absence of one particular translation product, although the corresponding mRNA was present (Costanzo \& Fox, 1990). The specificity of translational activation is determined by $5^{\prime}$-UTL of mRNAs, as shown by in vivo translation experiments of chimeric transcripts with 5 '-UTLs of COX2, $C O X 3$ and $C O B$ fused to each other's coding sequences. Translation clearly depended on the translational activator proteins specified by the 5'-UTL (Rodel \& Fox, 1987; Costanzo \& Fox, 1988; Mulero \& Fox, 1993a).

Respiratory deficiencies due to alterations in Cbs1p or Cbs2p, two proteins required for translation of $C O B$ mRNA, were overcome by mitochondrial mutations replacing the original leader by the $5^{\prime}$-UTL of ATP9 (Rodel, 1986 ; 1997). Mutation in the third gene CBP6, whose product is apparently involved in translation of $C O B$ mRNA, was not by-passed by attaching the $5^{\prime}$-UTL of ATP9, indicating that not all translational activators interact with 5'-UTLs (Dieckmann \& Tzagaloff, 1985; Dieckmann \& Staples, 1994). A similar situation was reported for COX1-specific activators, Mss51p and Pet309p (Decoster et al., 1990; Manthey \& McEwen, 1995). The phenotype of pet309 null mutation was suppressed by mtDNA rearrangements that placed a new 5 '-UTL in COX1 mRNA, but no such bypass of the mss51 mutation was observed. This may suggest an additional function or a different role of Mss51 and Cbp6 proteins in the translational activator complexes.

There has been limited success in determining the target sequences within $5^{\prime}$-UTLs of COX3, $C O B$ and COX2 mRNA, the three best studied genes (Costanzo \& Fox, 1993; Wiesenberger et al., 1995; Mittelmeier \& Dieckman, 1995; Dunstan et al., 1997).

Genetic data strongly support the idea of a direct interaction between translational activators and $5^{\prime}$-UTLs. The mutations localized in COX3 5'-UTL were suppressed by alterations of Pet122 or by overproduction of Pet494 activator proteins. Similarly, a mutation affecting $5^{\prime}$-UTL of COX2 mRNA was overcome by a single substitution or by an increased dosage of wild-type Pet111 activator protein (Mulero \& Fox, 1993b; Costanzo \& Fox, 1993; Wiesenberger et al., 1995).

For one activator protein, Pet122p, a direct interaction with the mitochondrial ribosome was suggested on the basis of genetic studies. The truncation of Pet122p led to the respiratory incompetence, but was suppressed by mutations in the genes encoding proteins of the ribosomal small subunit, Mrp1p, Mrp17p and Pet123p, as well as the Pet127 protein affecting mitochondrial RNA stability (Haffter \& Fox, 1992; McMullin et al., 1990; Haffter et $a l ., 1991 ; 1990)$. It is interesting to note that all ribosomal proteins that were picked up in this screen do not show any homology with known proteins and seem to fulfil functions unique to the mitochondrial system. The membrane-localized Pet127p is involved in mitochondrial mRNA surveillance system 
(Wiesenberger \& Fox, 1997; Węgierski et al., 1998).

Several lines of evidence demonstrated that the COX3-specific activators, Pet54p, Pet$122 p$ and Pet494p, form a complex. First, the missense pet54 mutation was suppressed in an allele-specific manner by a missense mutation affecting Pet122p (Brown et al., 1994). Second, pairwise interactions between Pet54p and Pet122p, as well as between Pet54p and Pet $494 \mathrm{p}$, were detected in the yeast two-hybrid system (Brown et al., 1994). Although Pet122p and Pet494p failed to interact with each other in the two-hybrid approach, the Pet122 as well as Pet54 proteins were found to be bound to Pet494p in co-immunoprecipitation experiments with specific Pet494p-directed serum, which argues strongly for the presence in the inner membrane of a trimeric complex (Fox, 1996a). So far there is no data supporting the existence of activator complexes specific for other mitochondrially translated proteins.

It is very likely that translational activation is the rate-limiting step in the whole mitochondrial gene expression process. The level of expression of some activator proteins is very low. A calculation based on a study of the PET494 promoter fused to a reporter sequence encoding beta-galactosidase gave the number of molecules between 2 and 60 per cell, depending on growth conditions. This result can be even overestimated since beta-galactosidase is very stable while Pet494p appears to be rather unstable (Fox, 1996b). Based on a comparison of expression levels the abundance of Pet111p is as low as that of Pet494p, which opens the possibility of subtle modulation of synthesis of the individual translation products in response to environmental changes. This, in fact, takes place in the case of some activator proteins regulated by the availability of oxygen and/or carbon source (reviewed by Grivell, 1995; Fox, 1996a).

Another very important feature of mitochondrial translational activators is their relatively common association with mitochondrial inner membrane. Two COX3-specific translational activators, Pet122p and Pet494p, are integral membrane proteins, substantially resistant to alkaline carbonate extraction. The third, Pet54p, is bound to the membrane fraction and can be extracted with alkaline carbonate which indicates its peripheral association with the membrane (McMullin \& Fox, 1993). A similar tendency has been observed for two activator proteins that are required for Cobp synthesis. Both Cbs1p and Cbs2p are membrane bound: Cbs2p is peripherally associated whereas Cbs1p is an integral membrane protein (Michaelis \& Rodel, 1990; Michaelis et al., 1991). Pet111p and Pet309p behave like integral mitochondrial membrane proteins when overexpressed to allow their detection (Fox, 1996a; Manthey et al., 1998).

It appears that mitochondrial ribosomes cannot simply initiate translation by interacting, with unassisted mitochondrial mRNAs in the matrix. The initiation of translation requires specific activators bound to the $5^{\prime}$-UTL which probably support the positioning of ribosomes over the correct initiation codon. Since the activators are associated with the membrane, the translation should occur on the surface of the mitochondrial inner membrane. Indeed, such coupling of the mitochondrial protein synthesis machinery with inner membrane has been considered for decades as an explanation for the firm binding of ribosomes to membranes (Bunn et al., 1970; Spithill et al., 1978; Marzuki \& Hibs, 1986). Additionally, there is evidence indicating co-translational insertion into membrane of at least some mitochondrial translation products (reviewed by Poyton et al., 1992). This would allow the nascent polypeptide chains to by synthesized near their site of assembly into multimeric respiratory complexes.

The data supporting such a scenario came from two sets of experiments. First, a mutation affecting $C B S 2$ was partially suppressed by overproduction of the protein encoded by the $A B C 1$ gene, implicated in the correct fold- 
ing or assembly of cytochrome $b$ (Bousquet et al., 1991).

Second, the productive tethering of the ribosome and translated mRNAs to the inner membrane facilitating the co-translational insertion of newly synthesized polypeptides was considered as a possible interpretation of experiments described recently by Sanchirico et al. (1998). This study was performed on chimeric COX2 and COX3 mRNAs with the 5' untranslated region derived from the mRNA encoding the soluble and hydrophilic ribosomal protein Var1. DNA sequences specifying these chimeric mRNAs were inserted into mtDNA at the VAR1 locus and expressed in the strains containing a plasmid that supplied a functional form of the Var1 protein, imported from the cytosol. Although both Cox $2 p$ and Cox3p were actively synthesized, such strains remained respiratory deficient and defective in the accumulation of Cox 2 and Cox3 subunits. This can be explained by assuming that both COX2 and COX3 mRNAs are translated at a location, probably in the matrix, that does not allow the productive assembly of subunits into the cytochrome oxidase complex leading to their rapid degradation. Interestingly, Cox $2 p$ synthesized as a precursor was correctly processed to the mature form which suggests that translocation, at least of the N-terminal part, through the inner membrane was not prevented, but could be either aberrant or in a wrong place.

The stability of mitochondrially synthesized proteins is also affected by alteration in mitochondrial ribosome. It was recently documented for some yeast strains that single amino acid substitution in the ribosomal protein Nam9 correlates with a decrease in the steady state level of some mitochondrially translated proteins and a lack of Cox $2 p$, although de novo mitochondrial protein synthesis is not changed. This finding suggests that Nam9p, like the translational activator proteins and the 5 '-untranslated region of the mRNA, is involved in productively attaching the ribosome to the mitochondrial inner membrane. Nam9-1p might be defective in this process, leading to problems in the biogenesis of Cox2p and possibly other respiratory chain components (Chacinska et al., 2000).

However, it is important to emphasize that 5 '-UTLs in mRNAs coding for hydrophobic proteins are interchangeable because Cox3 translated from chimeric mRNA with $C O B$ 5 '-UTL finds its way into the active cytochrome $c$ oxidase, allowing cells to respire (Fox, 1996a). On the other hand, translation of a mitochondrial mRNA under the control of membrane-bound activators is not sufficient to insert a soluble reporter protein into the inner membrane (Steele et al., 1996).

The facts presented above lead to speculations about the advantages of such a complicated and specialized system of distinct translational activators for assembly of respiratory enzymes. The higher order organization of the mitochondrial protein synthesis machinery, including translational activators, and proteins required for post-translational events, may exist at discrete sites in the inner membrane allowing synthesis and membrane insertion of the polypeptides in a defined topological orientation.

\section{EXPORT OF PROTEINS FROM THE MITOCHONDRIAL MATRIX}

Among the proteins synthesized on mitochondrial ribosomes, the subunit 2 of cytochrome $c$ oxidase (Cox2) is particularly interesting because it is synthesized as a precursor with an N-terminal leader peptide consisting of 15 amino-acid residues, that is removed upon translocation through the inner membrane (Sevarino \& Poyton, 1980; Pratje \& Guiard, 1986). The leader peptide is essential for the accumulation of functional Cox $2 p$ and most likely initiates its insertion into the membrane (Torello et al., 1997; He \& Fox, 1997). In the cox2 mutants lacking the presequence the defect is bypassed by mtDNA re- 
arrangement that results in a fusion of the sequence coding for the amino-terminal part of the Cob protein to the Cox 2 coding sequence (Torello et al., 1997).

The products of five nuclear genes, IMP1, IMP2, SOM1, OXA1 and COX20 were found to be involved directly or indirectly in the removal of the signal sequence since mutations affecting these genes prevented the processing of the Cox 2 precursor.

IMP1 and IMP2 code for subunits of the mitochondrial inner membrane protease 1 that is responsible not only for the maturation of the Cox2 subunit but also for the second proteolytic step of processing of some intermembrane space proteins synthesized and imported from the cytosol (Behrens et al., 1991; Schneider et al., 1991). Two subunits of this enzyme are localized on the intermembrane face of the inner membrane and display nonoverlapping specificity. Imp1p recognizes Cox $2 \mathrm{p}$, cytochrome $b_{2}$ and $\mathrm{NADH}$ cytochrome $b_{5}$ reductase $(\mathrm{Mcr} 1 \mathrm{p})$ as the substrates whereas Imp2p is required for the processing of cytochrome $c_{1}$ and cytochrome $c$ peroxidase as well as for the stability of Imp1p (Pratje \& Guiard, 1986; Hahne et al., 1994; Nunnari et al., 1993).

Another protein most likely required for the activity of the mitochondrial inner membrane protease is Som1p. SOM1 was identified as a multicopy suppressor of a mutation in the IMP1 gene. Deletion of the SOM1 gene led to the non-respiratory phenotype, strong reduction of cytochrome $b_{2}$ and accumulation of the Cox2 precursor. Thus, the small $8.4 \mathrm{kDa}$ inner membrane Som 1 protein appears to be a factor essential for correct functioning of the Imp1 protease (Esser et al., 1996; Bauerfeind et al., 1998).

Since the cleavage of the Cox 2 precursor occurs on the outside surface of the inner membrane and other products of mitochondrial translation contain at least one hydrophilic tail exposed into the intermembrane space (Poyton et al., 1992), a mechanism responsible for their translocation out of the matrix should be present in mitochondria. In opposition to extensive studies on the mechanisms of protein import from the cytoplasm into the mitochondria, very little is known about proteins responsible for the export of mitochondrially synthesized polypeptides (reviewed by Tokatlidis \& Schatz, 1999). The only known component involved in this process is Oxa1p, a conserved integral inner membrane protein (Bonnefoy et al., 1994a; 1994b; Kermorgant et $a l .$, 1997). Oxa1p is required for the export of $\mathrm{N}$ - and C-terminal tails of Cox $2 \mathrm{p}$, being responsible for an important step of cytochrome $c$ oxidase biogenesis, and also plays a role in ATP-synthase formation (Bauer et al., 1994; Bonnefoy et al., 1994b; Altamura et al., 1996; He \& Fox, 1997; Hell et al., 1997; Kermorgant et al., 1997; Meyer et al., 1997). Oxa1p has been reported to interact physically with nascent chains synthesized in mitochondria, including Cox $2 p$ and Cox $3 p$. In addition to its function in the biogenesis of mitochondrially encoded proteins, Oxa1p appears to play an even more general role in translocation of some imported nuclear encoded proteins, including Oxa1p itself. The export from the matrix, like other pathways involved in the translocation across the inner mitochondrial membrane, requires a membrane potential and resembles the sec-independent sorting of membrane proteins in prokaryotes (Hell et al., 1998; Herrmann et al., 1997; Rojo et al., 1999). Thus, Oxa1p represents a central component of the general machinery that translocates hydrophobic proteins from the matrix into the inner mitochondrial membrane. It is worth to note in this context that, surprisingly, the conserved function of Oxa1p was by-passed by specific mutations affecting cytochrome $c_{1}$ that decreased its hydrophobicity and membrane association but not electron transfer (Hamel et al., 1998).

Recently, the COX20 gene was identified by complementation in a mutant defective in Cox 2 processing. The cox20 mutations resulted in accumulation of Cox 2 precursor although they did not affect export or process- 
ing directly. Cox20p was found to be bound to the precursor and mature form of Cox $2 p$ which suggested its chaperone-like function necessary for the cleavage and subsequent interaction of mature Cox 2 subunit with other polypeptides of cytochrome $c$ oxidase in the assembly step (Hell et al., 2000).

In addition to the pathway of cytochrome $c$ oxidase formation, intriguing data came from study of the export of artificial reporter protein, Arg8p, fused to Cox2-presequence. The translocation of this mitochondrially encoded fusion protein across the inner membrane was blocked by mutation in the PNT1 gene. The product of this gene, originally identified as conferring resistance of the cells to the antibiotic pentamidine, was shown to be an integral inner membrane protein. Although the null mutant did not affect either the respiratory growth capacity or the export of wild-type Cox2 subunit in S. cerevisiae, the deletion of its homologue in Kluyveromyces lactis resulted in a clearly non-respiratory phenotype and a defect in the assembly of KlCox2 subunit that appeared to be due to a block in translocation of the C-terminal part. This demonstrates that the Pnt1 protein in $K$. lactis plays an important physiological role and suggests that an overlapping function may exist in $S$. cerevisiae. Since the pnt1 deletion caused increased sensitivity to $\mathrm{H}_{2} \mathrm{O}_{2}$ and accumulation significantly more $\left[\mathrm{rho}^{-}\right]$mutations under respiratory growth conditions, one may hypothesize that Pnt1p plays a role in the mitochondrial "detoxification" system promoting the transport of components damaged by oxidative stress out of the matrix (He \& Fox, 1999).

\section{TURN-OVER AND QUALITY CONTROL OF MITOCHONDRIAL MEMBRANE PROTEINS}

It has been known for a long time that mitochondria contain their own protein degradation system and now it is clear that all known mitochondrial proteases are homologous to prokaryotic ATP-dependent proteases. Mitochondrial soluble and membrane-bound enzymes differ in specificity.

The inner mitochondrial membrane contains proteins related to bacterial $\mathrm{FtsH}$ ATP-dependent metalloproteases, which are members of the AAA family of ATPases associated with diverse cellular functions. These proteins are responsible for the degradation of incomplete and unassembled newly synthesized mitochondrial translation products (reviewed by Suzuki et al., 1997). The YME1 gene was identified by complementation of the mitochondrial DNA escape phenotype (Thorsness et al., 1993) and independently by complementation in a mutant defective in the degradation of unassembled Cox2 subunit of cytochrome $c$ oxidase (Nakai et al., 1995). Yme1p forms an inner membrane complex of approximately $850 \mathrm{kDa}$ with the active sites on the intermembrane space surface, that can degrade a reporter protein anchored in the mitochondrial inner membrane (Leonhard et al., 1996). Two genes, AFG3 and RCA1, encode components of the second complex present in the inner membrane that exposes its catalytic sites to the mitochondrial matrix. A coordinated proteolytic and chaperone-like function has been reported for the Afg3/Rca1 complex (Pajic et al., 1994; Guzelin et al., 1996; Arlt et al., 1996; 1998). Both rca1 and afg3 mutants synthesize subunits of respiratory complexes at normal levels and import the cytoplasmically synthesized subunits as efficiently as the wild type, but the assembly of respiratory complexes is affected (Paul \& Tzagoloff, 1995). Additionally, the proteolytically inactive variants of Afg3p and Rca1p were able to complement the respiratory deficiency caused by the lack of Afg3p and Rca1p, suggesting that the protease function is not essential for the maintenance of respiratory competence (Guzelin et al., 1996; Arlt et al., 1996). Indeed, the chaperone-like activity of the Afg3/Rca1 complex was required for the assembly of mitochondrial ATP synthase (Arlt et al., 1996). 
The observation that the $O X A 1$ gene acts as a multicopy suppressor of respiratory deficiency of afg3- and rca 1-null mutants suggests an intriguing connection between the efficiency of translocation and the Afg3p/Rca1pdependent events, supporting the assembly function of the protease complex (Rep et al., 1996). Such a bypass of afg3- and rca 1-null mutations was also possible when the $M B A 1$ gene encoding an inner membrane-associated protein was overexpressed, indicating its related role in the biogenesis of the respiratory chain (Rep \& Grivell, 1996).

Assembly and degradation of proteins appear to be opposite processes, but ATP-dependent proteases may be involved at the step of decision between assembly or degradation events, carrying out the quality control of polypeptides and regulating the subunit stoichiometry of protein complexes. This could be achieved by holding of newly synthesized proteins until other partner subunits become available (Suzuki et al., 1997; Grivell et al., 1999).

\section{ASSEMBLY OF RESPIRATORY COMPLEXES}

In contrast to the availability of a broad spectrum of structural data on ATP synthase, cytochrome $c$ oxidase and $b c_{1}$ complexes, very little is known about the processes involved in their assembly.

The list of nuclear genes that have been identified as affecting late steps of the respiratory chain biogenesis is still growing. The Cox 10 and Cox11 proteins that were originally reported to be essential for a posttranslational step of cytochrome $c$ oxidase biogenesis are in fact required for the biosynthesis of heme A (Nobrega et al., 1990; Tzagaloff et al., 1993; Glerum \& Tzagaloff, 1994; Hiser et al., 2000). Cox $17 p$ and Sco1p function as carrier proteins in the delivery of copper from the cytosol to the mitochondrial Cox1 and Cox2 subunits of cytochrome $c$ oxidase (Glerum et al., 1996a; 1996b; Rentzsch et al., 1999). The point mutants in COX17 and SCO1 genes can be rescued by alterations in the Sco 2 protein that shows homology to Sco1p and has a potential copper-binding domain (Glerum et al., 1996a). The above mentioned Cox $20 \mathrm{p}$ acts probably as a membrane-bound chaperone (Hell et al., 2000).

In the case of several other proteins including Pet100, Pet117, Pet191, Cox14 and Cox15 it is known only that they play an undefined role at some stage after the synthesis of the mitochondrially encoded subunits of cytochrome $c$ oxidase. Strains bearing mutations in the genes encoding those proteins lack, or have a decreased level, of the studied subunits or of the whole complex, and display respiratory incompetence, although the de novo synthesis of proteins is not impaired (Church et al., 1996; McEwen et al., 1993; Glerum et al., 1995; 1997).

It has been demonstrated recently that prohibitins, ubiquitous, abundant and strongly conserved proteins, play a role in the stabilization of mitochondrially synthesized polypeptides (Steglich et al., 1999; Nijtmans et al., 2000). The yeast homologues of mammalian prohibitin and prohibitin-related protein, Phb1p and Phb2p, respectively, form a complex in the inner mitochondrial membrane, which probably contains $12-16$ copies each of Phb1p and Phb2p and does not contain any other proteins (Snyers et al., 1998; Nijtmans et al., 2000). Pulse-chase experiments with mitochondria showed that the Phb1/2 complex is able to stabilize newly synthesized Cox $2 p$ and Cox3p that remain associated with $\mathrm{Phb} 1 / 2$ until being assembled into the oxidase complex. This suggests the possibility that the Phb1/2 complex protects newly synthesized mitochondrial proteins from proteolysis and functions as a membrane bound chaperone (Nijtmans et al., 2000). Moreover, expression of the $\mathrm{Phb} 1 / 2$ complex is increased in a yeast strain with altered Mss51p, the translational activator of COX1. Transient induction of the complex due to imbalance in the mitochon- 
drially encoded subunits in the mss51 mutant, might suggest a holding function, preventing the synthesized peptides from misfolding (Nijtmans et al., 2000).

The assembly of $\mathrm{F}_{0} \mathrm{~F}_{1}$-ATPase (complex V) requires the Atp10, Atp11 and Atp12 proteins. Atp $11 p$ and Atp $12 p$ are localized in the matrix and are responsible for the biogenesis of $\mathrm{F}_{1}$, whereas the membrane localized Atp10p functions in the assembly of the $F_{0}$ component of mitochondrial ATP synthase (Ackerman \& Tzagaloff, 1990; Ackerman et al., 1992; Bowman et al., 1991; Wang \& Ackerman, 1998; 2000).

The bc 1 complex is dependent on the action of the $A B C 1$ gene product that was originally identified as a multicopy suppressor of a $C O B$ mRNA translational defect. Additionally, three proteins, Cpb3, Cpb4 and Bcs1, seem to be involved in the process of assembly. In the mutants affecting the Abc1, Cpb3 and Cpb4 proteins the absence of either NADH-succinate dehydrogenase activity or spectrally detectable cytochrome $b$ were observed, whereas alteration in Bcs1p, a member of the AAA family, led to a decrease in the FeS protein content indicating its role specifically in biogenesis of the Rieske iron-sulfur protein (Wu \& Tzagaloff, 1989; Bousquet et al., 1991; Nobrega et al., 1992; Crivellone, 1994; Brasseur et al., 1997).

A remarkable feature of the whole set of factors discussed above is that the majority of them display no similarity to known chaperone proteins. The only exception known so far are prohibitins that show weak homology to members of hsp60 family (Nijtmans et al., 2000). Thus, it seems reasonable to suppose that, in contrast to the matrix environment where the "classical" chaperones function, other mechanisms, specific for mitochondrial inner membrane, are involved in the formation of the respiratory chain complexes.

\section{CONCLUDING REMARKS}

Correct localization and assembly of newly synthesized product into higher order structures is one of the fundamental processes of the cell. The importance for the cellular economy of coordination between translation and those post-translational events has driven the evolution of unique and sometimes unexpected regulatory systems. Coupling of mitochondrial translation with export, quality control and assembly might be advantageous for formation of respiratory complexes in yeast mitochondria. A still growing list of genes involved in this process suggests that so far we really have little idea of what is going on at the late stage of proteins biogenesis in the inner mitochondrial membrane.

We thank Dr. Aleksandra Dmochowska for critical reading of the manuscript

\section{R E F E R E N C E S}

Ackerman, S.H. \& Tzagoloff, A. (1990) ATP 10, a yeast nuclear gene required for the assembly of the mitochondrial F1-F0 complex. J. Biol. Chem. 265, 9952-9959.

Ackerman, S.H., Martin, J. \& Tzagoloff, A. (1992) Characterization of ATP11 and detection of the encoded protein in mitochondria of Saccharomyces cerevisiae. J. Biol. Chem. 267, 7386-7394.

Altamura, N., Capitanio, N., Bonnefoy, N., Papa, S. \& Dujardin, G. (1996) The Saccharomyces cerevisiae OXA1 gene is required for the correct assembly of cytochrome $c$ oxidase and oligomycin-sensitive ATP synthase. FEBS Lett. 382, 111-115.

Arnold, I., Pfeiffer, K., Neupert, W., Stuart, R.A. \& Schägger, H. (1999) ATP synthase of yeast mitochondria. Isolation of subunit $\mathrm{j}$ and disruption of the ATP18 gene. J. Biol. Chem. 274, $36-40$. 
Arlt, H., Tauer, R., Feldmann, H., Neupert, W. \& Langer, T. (1996) The YTA10-12 complex, an AAA protease with chaperone-like activity in the inner membrane of mitochondria. Cell $\mathbf{8 5}$, $875-885$.

Arlt, H., Steglich, G., Perryman, R., Guiard, B., Neupert, W. \& Langer, T. (1998) The formation of respiratory chain complexes in mitochondria is under the proteolytic control of the m-AAA protease. EMBO J. 17, 4837-4847.

Bauer, M., Behrens, M., Esser, K., Michaelis, G. \& Pratje, E. (1994) PET1402, a nuclear gene required for proteolytic processing of cytochrome oxidase subunit 2 in yeast. Mol. Gen. Genet. 245, 272-278.

Bauerfeind, M., Esser, K. \& Michaelis, G. (1998) The Saccharomyces cerevisiae SOM1 gene: Heterologous complementation studies, homologues in other organisms, and association of the gene product with the inner mitochondrial membrane. Mol. Gen. Genet. 257, $635-640$.

Behrens, M., Michaelis, G. \& Pratje, E. (1991) Mitochondrial inner membrane protease 1 of Saccharomyces cerevisiae shows sequence similarity to the Escherichia coli leader peptidase. Mol. Gen. Genet. 228, 167-176.

Biswas, T.K. \& Getz, G.S. (1999) The single amino acid changes in the yeast mitochondrial $\mathrm{S} 4$ ribosomal protein cause temperature-sensitive defect in the accumulation of mitochondrial 15S rRNA. Biochemistry 38, 13042-13054.

Boguta, M., Dmochowska, A., Borsuk, P., Wrobel, K., Gargouri, A., Lazowska, J., Slonimski, P.P., Szczesniak, B. \& Kruszewska, A. (1992) NAM9 nuclear suppressor of mitochondrial ochre mutations in Saccharomyces cerevisiae codes for a protein homologous to $\mathrm{S} 4$ ribosomal proteins from chloroplasts, bacteria, and eucaryotes. Mol. Cell. Biol. 12, 402-412.

Boguta, M., Chacinska, A., Murawski, M. \& Szczesniak, B. (1997) Expression of the yeast NAM9 gene coding for mitochondrial ribosomal protein. Acta Biochim. Polon. 44, 251-258.

Bonnefoy, N. \& Fox, T.D. (2000) In vivo analysis of mutated initiation codons in the mitochondrial COX2 gene of Saccharomyces cerevisiae fused to the reporter gene ARG8m reveals lack of downstream reinitiation. Mol. Gen. Genet. 262, 1036-1046.

Bonnefoy, N., Kermorgant, M., Groudinsky, O., Minet, M., Slonimski, P.P. \& Dujardin, G. (1994a) Cloning of a human gene involved in cytochrome oxidase assembly by functional complementation of an oxa1-mutation in Saccharomyces cerevisiae. Proc. Natl. Acad. Sci. U.S.A. 91, 11978-11982.

Bonnefoy, N., Chalvet, F., Hamel, P., Slonimski, P.P. \& Dujardin, G. (1994b) OXA1, a Saccharomyces cerevisiae nuclear gene whose sequence is conserved from prokaryotes to eukaryotes controls cytochrome oxidase biogenesis. J. Mol. Biol. 239, 201-212.

Borst, P. \& Grivell, L.A. (1971) Mitochondrial ribosomes. FEBS Lett. 13, 73-88.

Bousquet, I., Dujardin, G. \& Slonimski, P.P. (1991) $\mathrm{ABC} 1$, a novel yeast nuclear gene has a dual function in mitochondria: It suppresses a cytochrome $b$ mRNA translation defect and is essential for the electron transfer in the bc 1 complex. EMBO J. 10, 2023-2031.

Bowman, S., Ackerman, S.H., Griffiths, D.E. \& Tzagoloff, A. (1991) Characterization of ATP12, a yeast nuclear gene required for the assembly of the mitochondrial F1-ATPase. $J$. Biol. Chem. 266, 7517-7523.

Brasseur, G., Tron, G., Dujardin, G., Slonimski, P.P. \& Brivet-Chevillotte, P. (1997) The nuclear $\mathrm{ABC} 1$ gene is essential for the correct conformation and functioning of the cytochrome $b c_{1}$ complex and the neighbouring complexes II and IV in the mitochondrial respiratory chain. Eur. J. Biochem. 246, 103-111.

Brown, N.G., Costanzo, M.C. \& Fox, T.D. (1994) Interactions among three proteins that specifically activate translation of the mitochondrial COX3 mRNA in Saccharomyces cerevisiae. Mol. Cell. Biol. 14, 1045-1053.

Bunn, C.L., Mitchell, C.H., Lukins, H.B. \& Linnane, A.W. (1970) A new class of cytoplasmically determined antibiotic resistant mutants in Saccharomyces cerevisiae. Proc. Natl. Acad. Sci. U.S.A. 67, 1233-1240. 
Chacinska, A., Boguta, M., Krzewska, J. \& Rospert, S. (2000) Prion dependent switching between respiratory competence and deficiency in the yeast nam9-1 mutant. Mol. Cell. Biol. 20, 7220-7229.

Church, C., Chapon, C. \& Poyton, R.O. (1996) Cloning and characterization of PET100, a gene required for the assembly of yeast cytochrome $c$ oxidase. J. Biol. Chem. 271, 18499-18450.

Colby, G., Wu, M. \& Tzagoloff, A. (1998) MTO1 codes for a mitochondrial protein required for respiration in paromomycin-resistant mutants of Saccharomyces cerevisiae. J. Biol. Chem. 273, 27945-27952.

Costanzo, M.C. \& Fox, T.D. (1988) Specific translational activation by nuclear gene products occurs in the $5^{\prime}$ untranslated leader of a yeast mitochondrial mRNA. Proc. Natl. Acad. Sci. U.S.A. 85, 2677-2681.

Costanzo, M.C. \& Fox, T.D. (1990) Control of mitochondrial gene expression in Saccharomyces cerevisiae. Annu. Rev. Genet. 24, 91-113.

Costanzo, M.C. \& Fox, T.D. (1993) Suppression of a defect in the $5^{\prime}$ untranslated leader of mitochondrial COX3 mRNA by a mutation affecting an mRNA-specific translational activator protein. Mol. Cell. Biol. 13, 4806-4813.

Crivellone, M.D. (1994) Characterization of CBP4, a new gene essential for the expression of ubiquinol-cytochrome $c$ reductase in Saccharomyces cerevisiae. J. Biol. Chem. 269, 2128421292.

Decoster, E., Simon, M., Hatat, D. \& Faye, G. (1990) The MSS51 gene product is required for the translation of the COX1 mRNA in yeast mitochondria. Mol. Gen. Genet. 224, 111-118.

Decoster, E., Vassal, A. \& Faye, G. (1993) MSS1, a nuclear-encoded mitochondrial GTPase involved in the expression of COX1 subunit of cytochrome $c$ oxidase. J. Mol. Biol. 232, $79-88$.

Dieckmann, C.L. \& Staples, R.R. (1994) Regulation of mitochondrial gene expression in Saccharomyces cerevisiae. Mol. Cell. Biol. 7, 177-184.
Dieckmann, C.L. \& Tzagoloff, A. (1985) Assembly of the mitochondrial membrane system. CBP6, a yeast nuclear gene necessary for synthesis of cytochrome b. J. Biol. Chem. 260, $1513-1520$.

Dmochowska, A., Konopinska, A., Krzymowska, M., Szczesniak, B. \& Boguta, M. (1995) The NAM9-1 suppressor mutation in a nuclear gene encoding ribosomal mitochondrial protein of Saccharomyces cerevisiae. Gene 162, 81-85.

Dunstan, H.M., Green-Willms, N.S. \& Fox, T.D. (1997) In vivo analysis of Saccharomyces cerevisiae COX2 mRNA 5'-untranslated leader functions in mitochondrial translation initiation and translational activation. Genetics 147, 87-100.

Esser, K., Pratje, E. \& Michaelis, G. (1996) SOM1, a small new gene required for mitochondrial inner membrane peptidase function in $S a c$ charomyces cerevisiae. Mol. Gen. Genet. 252, 437-445.

Folley, L.S. \& Fox, T.D. (1994) Reduced dosage of genes encoding ribosomal protein S18 suppresses a mitochondrial initiation codon mutation in Saccharomyces cerevisiae. Genetics 137, 369-379.

Fox, T.D. (1996a) Genetics of mitochondrial translation; in Translational Control, pp. 733-758, Cold Spring Harbor Laboratory Press.

Fox, T.D. (1996b) Translational control of endogenous and recoded nuclear genes in yeast mitochondria: Regulation and membrane targeting. Experientia 52, 1130-1135.

Fox, T.D. \& Weiss-Brummer, B. (1980) Leaky +1 and -1 frameshift mutations at the same site in a yeast mitochondrial gene. Nature 288, 60-63.

Glerum, D.M. \& Tzagoloff, A. (1994) Isolation of a human cDNA for heme A: farnesyltransferase by functional complementation of a yeast cox10 mutant. Proc. Natl. Acad. Sci. U.S.A. 91, 8452-8456.

Glerum, D.M., Koerner, T.J. \& Tzagoloff, A. (1995) Cloning and characterization of COX14, whose product is required for assembly of yeast 
cytochrome oxidase J. Biol. Chem. 270, 15585-15590.

Glerum, D.M., Shtanko, A. \& Tzagoloff, A. (1996a) SCO1 and SCO2 act as high copy suppressors of a mitochondrial copper recruitment defect in Saccharomyces cerevisiae. J. Biol. Chem. 271, 20531-20535.

Glerum, D.M., Shtanko, A. \& Tzagoloff, A. (1996b) Characterization of COX17, a yeast gene involved in copper metabolism and assembly of cytochrome oxidase. J. Biol. Chem. 271, 14504-14509.

Glerum, D.M., Muroff, I., Jin, C. \& Tzagoloff, A. (1997) COX15 codes for a mitochondrial protein essential for the assembly of yeast cytochrome oxidase. J. Biol. Chem. 272, 1908819094.

Graack, H.R. \& Wittmann-Liebold, B. (1998) Mitochondrial ribosomal proteins (MRPs) of yeast. Biochem. J. 329, 433-448.

Green-Willms, N.S., Fox, T.D. \& Costanzo, M.C. (1998) Functional interactions between yeast mitochondrial ribosomes and mRNA 5' untranslated leaders. Mol. Cell. Biol. 18, 18261834.

Grivell, L.A. (1995) Nucleo-mitochondrial interactions in mitochondrial gene expression. Crit. Rev. Biochem. Mol. Biol. 30, 121-164.

Grivell, L.A., Artal-Sanz, M., Hakkaart, G., de Jong, L., Nijtmans, L.G., van Oosterum, K., Siep, M. \& van der Spek, H. (1999) Mitochondrial assembly in yeast. FEBS Lett. 452, 57-60.

Guzelin, E., Rep, M. \& Grivell, L.A. (1996) Afg3p, a mitochondrial ATP-dependent metalloprotease, is involved in degradation of mitochondrially-encoded Cox1, Cox3, Cob, Su6, Su8 and Su9 subunits of the inner membrane complexes III, IV and V. FEBS Lett. 381, 42-46.

Haffter, P., McMullin, T.W. \& Fox, T.D. (1990) A genetic link between an mRNA-specific translational activator and the translation system in yeast mitochondria. Genetics 125, 495-503.

Haffter, P., McMullin, T.W. \& Fox, T.D. (1991) Functional interactions among two yeast mitochondrial ribosomal proteins and an mRNA- specific translational activator. Genetics $\mathbf{1 2 7}$, 319-326.

Haffter, P. \& Fox, T.D. (1992) Suppression of carboxy-terminal truncations of the yeast mitochondrial mRNA-specific translational activator PET122 by mutations in two new genes, MRP17 and PET127. Mol. Gen. Genet. 235, 64-73.

Hahne, K., Haucke, V., Ramage, L. \& Schatz, G. (1994) Incomplete arrest in the outer membrane sorts NADH-cytochrome $b_{5}$ reductase to two different submitochondrial compartments. Cell 79, 829-839.

Hamel, P., Lemaire, C., Bonnefoy, N., BrivetChevillotte, P. \& Dujardin, G. (1998) Mutations in the membrane anchor of yeast cytochrome $c_{1}$ compensate for the absence of Oxa1p and generate carbonate-extractable forms of cytochrome $c_{1}$. Genetics 150, 601-611.

He, S. \& Fox, T.D. (1997) Membrane translocation of mitochondrially coded Cox2p: Distinct requirements for export of $\mathrm{N}$ and $\mathrm{C}$ termini and dependence on the conserved protein Oxa1p. Mol. Biol. Cell 8, 1449-1460.

He, S. \& Fox, T.D. (1999) Mutations affecting a yeast mitochondrial inner membrane protein, pnt1p, block export of a mitochondrially synthesized fusion protein from the matrix. Mol. Cell. Biol. 19, 6598-6607.

Hell, K., Herrmann, J., Pratje, E., Neupert, W. \& Stuart, R.A. (1997) Oxa1p mediates the export of the $\mathrm{N}$ - and C-termini of pCoxII from the mitochondrial matrix to the intermembrane space. FEBS Lett. 418, 367-370.

Hell, K., Herrmann, J.M., Pratje, E., Neupert, W. \& Stuart, R.A. (1998) Oxa1p, an essential component of the $\mathrm{N}$-tail protein export machinery in mitochondria. Proc. Natl. Acad. Sci. U.S.A. 95, 2250-2255.

Hell, K., Tzagoloff, A., Neupert, W. \& Stuart, R.A. (2000) Identification of Cox20p, a novel protein involved in the maturation and assembly of cytochrome oxidase subunit 2. J. Biol. Chem. 275, 4571-4578.

Herrmann, J.M., Neupert, W. \& Stuart, R.A. (1997) Insertion into the mitochondrial inner 
membrane of a polytopic protein, the nuclear-encoded Oxa1p. EMBO J. 16, 22172226 .

Hiser, L., Di Valentin, M., Hamer, A.G. \& Hosler, J.P. (2000) Cox11p is required for stable formation of the $\mathrm{Cu}(\mathrm{B})$ and magnesium centers of cytochrome $c$ oxidase. J. Biol. Chem. 275, 619-623.

Hudspeth, M.E., Ainley, W.M., Shumard, D.S., Butow, R.A. \& Grossman, L.I. (1982) Location and structure of the var1 gene on yeast mitochondrial DNA: Nucleotide sequence of the 40.0 allele. Cell 30, 617-626.

Kermorgant, M., Bonnefoy, N. \& Dujardin, G. (1997) Oxa1p, which is required for cytochrome $c$ oxidase and ATP synthase complex formation, is embedded in the mitochondrial inner membrane. Curr. Genet. 31, 302-307.

Leonhard, K., Herrmann, J.M., Stuart, R.A., Mannhaupt, G., Neupert, W. \& Langer, T. (1996) AAA proteases with catalytic sites on opposite membrane surfaces comprise a proteolytic system for the ATP-dependent degradation of inner membrane proteins in mitochondria. EMBO J. 15, 4218-4229.

Mason, T.L.., Pan, C., Sanchirico, M.E. \& SirumConnolly, K. (1996) Molecular genetics of the peptidyl transferase center and the unusual Var1 protein in yeast mitochondrial ribosomes. Experientia 121, 1148-1156.

Manthey, G.M. \& McEwen, J.E. (1995) The product of the nuclear gene PET309 is required for translation of mature mRNA and stability or production of intron-containing RNAs derived from the mitochondrial COX1 locus of Saccharomyces cerevisiae. EMBO J. 14, 4031-4043.

Manthey, G.M., Przybyla-Zawislak, B.D. \& McEwen, J.E. (1998) The Saccharomyces cerevisiae Pet309 protein is embedded in the mitochondrial inner membrane. Eur. J. Biochem. 155, 156-161.

Marzuki, S. \& Hibbs, A.R. (1986) Are all mitochondrial translation products synthesized on membrane-bound ribosomes? Biochim. Biophys. Acta 866, 120-124.

McEwen, J.E., Hong, K.H., Park, S. \& Preciado, G.T. (1993) Sequence and chromosomal local- ization of two PET genes required for cytochrome $c$ oxidase assembly in Saccharomyces cerevisiae. Curr. Genet. 23, 9-14.

McKee, E.E. \& Poyton, R.O. (1984) Mitochondrial gene expression in Saccharomyces cerevisiae. I. Optimal conditions for protein synthesis in isolated mitochondria. J. Biol. Chem. 259, 9320-9331.

McMullin, T.W. \& Fox, T.D. (1993) COX3 mRNA-specific translational activator proteins are associated with the inner mitochondrial membrane in Saccharomyces cerevisiae. J. Biol. Chem. 268, 11737-11741.

McMullin, T.W., Haffter, P. \& Fox, T.D. (1990) A novel small-subunit ribosomal protein of yeast mitochondria that interacts functionally with an mRNA-specific translational activator. Mol. Cell. Biol. 10, 4590-4595.

Meyer, W., Bomer, U. \& Pratje, E. (1997) Mitochondrial inner membrane bound Pet1402 protein is rapidly imported into mitochondria and affects the integrity of the cytochrome oxidase and ubiquinol-cytochrome $c$ oxidoreductase complexes. Biol. Chem. 378, 13731379.

Michaelis, U. \& Rodel, G. (1990) Identification of CBS2 as a mitochondrial protein in Saccharomyces cerevisiae. Mol. Gen. Genet. 223, 394-400.

Michaelis, U., Korte, A. \& Rodel, G. (1991) Association of cytochrome $b$ translational activator proteins with the mitochondrial membrane: Implications for cytochrome $b$ expression in yeast. Mol. Gen. Genet. 230, 177-185.

Mittelmeier, T.M. \& Dieckmann, C.L. (1995) In vivo analysis of sequences required for translation of cytochrome $b$ transcripts in yeast mitochondria. Mol. Cell. Biol. 15, 780-789.

Mulero, J.J. \& Fox, T.D. (1993a) PET111 acts in the $5^{\prime}$-leader of the Saccharomyces cerevisiae mitochondrial COX2 mRNA to promote its translation. Genetics 133, 509-516.

Mulero, J.J. \& Fox, T.D. (1993b) Alteration of the Saccharomyces cerevisiae COX2 mRNA 5'-untranslated leader by mitochondrial gene replacement and functional interaction with the 
translational activator protein PET111. Mol. Biol. Cell, 4, 1327-1335.

Mulero, J.J. \& Fox, T.D. (1994) Reduced but accurate translation from a mutant AUA initiation codon in the mitochondrial COX2 mRNA of Saccharomyces cerevisiae. Mol. Gen. Genet. 242, 383-390.

Mulero, J.J., Rosenthal, J.K. \& Fox, T.D. (1994) PET112, a Saccharomyces cerevisiae nuclear gene required to maintain $\mathrm{rho}^{+}$mitochondrial DNA. Curr. Genet. 25, 299-304.

Myers, A.M., Pape, L.K. \& Tzagoloff, A. (1985) Mitochondrial protein synthesis is required for maintenance of intact mitochondrial genomes in Saccharomyces cerevisiae. EMBO J. 4, 2087-2092.

Nagata, S., Tsunetsungu-Yokota, Y., Naito, A. \& Kaziro, Y. (1983) Molecular cloning and sequence determination of the nuclear gene coding for mitochondrial elongation factor $\mathrm{Tu}$ of S. cerevisiae. Proc. Natl. Acad. Sci. U.S.A. 80, 6192-6196.

Nakai, T., Yasuhara, T., Fujiki, Y. \& Ohashi, A. (1995) Multiple genes, including a member of the AAA family, are essential for degradation of unassembled subunit 2 of cytochrome $c$ oxidase in yeast mitochondria. Mol. Cell. Biol. 15, 4441-4452.

Nijtmans, L.G., de Jong, L., Artal Sanz, M., Coates, P.J., Berden, J.A., Back, J.W., Muijsers, A.O., van der Spek, H. \& Grivell, L.A. (2000) Prohibitins act as a membranebound chaperone for the stabilization of mitochondrial proteins. EMBO J. 19, 2444-2451.

Nobrega, M.P., Nobrega, F.G. \& Tzagoloff, A. (1990) COX10 codes for a protein homologous to the ORF1 product of Paracoccus denitrificans and is required for the synthesis of yeast cytochrome oxidase. J. Biol. Chem. 265, 14220-14226.

Nobrega, F.G., Nobrega, M.P. \& Tzagoloff, A. (1992) BCS1, a novel gene required for the expression of functional Rieske iron-sulfur protein in Saccharomyces cerevisiae. EMBO J. 11, 3821-3829.

Nunnari, J., Fox, T.D. \& Walter, P. (1993) A mitochondrial protease with two catalytic subunits of nonoverlapping specificities. Science $\mathbf{2 6 2}$, 1997-2004.

Pajic, A., Tauer, R., Feldmann, H., Neupert, W. \& Langer, T. (1994) Yta10p is required for the ATP-dependent degradation of polypeptides in the inner membrane of mitochondria. FEBS Lett. 353, 201-206.

Paul, M.F. \& Tzagoloff, A. (1995) Mutations in RCA1 and AFG3 inhibit F1-ATPase assembly in Saccharomyces cerevisiae. FEBS Lett. 373, $66-70$.

Pel, H.J. \& Grivell, L.A. (1994) Protein synthesis in mitochondria. Mol. Biol. Rep. 19, 183-194.

Pel, H.J., Tzagoloff, A. \& Grivell, L.A. (1992a) The identification of 18 nuclear genes required for the expression of the yeast mitochondrial gene encoding cytochrome $c$ oxidase subunit 1 . Curr. Genet. 21, 139-146.

Pel, H.J., Maat, C., Rep, M. \& Grivell, L.A. (1992b) The yeast nuclear gene MRF1 encodes a mitochondrial peptide chain release factor and cures several mitochondrial RNA splicing defects. Nucleic Acids Res. 20, 6339-6346.

Pel, H.J., Rep, M., Dubbink, H.J. \& Grivell, L.A. (1993) Single point mutations in domain II of the yeast mitochondrial release factor mRF-1 affect ribosome binding. Nucleic Acids Res. 21, $5308-5315$.

Poyton, R.O., Duhl, D.M.J. \& Clarkson, G.H.D. (1992) Protein export from the mitochondrial matrix. Trends Cell. Biol. 2, 369-375.

Poyton, R.O., Goehring, B., Droste, M., Sevarino, K.A., Allen, L.A. \& Zhao, X.J. (1995) Cytochrome-c oxidase from Saccharomyces cerevisiae. Methods Enzymol. 260, 97-116.

Pratje, E. \& Guiard, B. (1986) One nuclear gene controls the removal of transient pre-sequences from two yeast proteins: One encoded by the nuclear the other by the mitochondrial genome. EMBO J. 5, 1313-1317.

Rentzsch, A., Krummeck-Weiss, G., Hofer, A., Bartuschka, A., Ostermann, K. \& Rodel, G. (1999) Mitochondrial copper metabolism in yeast: Mutational analysis of Sco1p involved in the biogenesis of cytochrome $c$ oxidase. Curr. Genet. 35, 103-108. 
Rep, M. \& Grivell, L.A. (1996) MBA1 encodes a mitochondrial membrane-associated protein required for biogenesis of the respiratory chain. FEBS Lett. 388, 185-188.

Rep, M., Nooy, J., Guelin, E. \& Grivell, L.A. (1996) Three genes for mitochondrial proteins suppress null-mutations in both Afg3 and Rca1 when over-expressed. Curr. Genet. 30, 206211.

Rodel, G. (1986) Two yeast nuclear genes, CBS1 and CBS2, are required for translation of mitochondrial transcripts bearing the 5 '-untranslated COB leader. Curr. Genet. 11, 41-45.

Rodel, G. (1997) Translational activator proteins required for cytochrome $b$ synthesis in Saccharomyces cerevisiae. Curr. Genet. 31, 375-379.

Rodel, G. \& Fox, T.D. (1987) The yeast nuclear gene CBS1 is required for translation of mitochondrial mRNAs bearing the cob $5^{\prime}$ untranslated leader. Mol. Gen. Genet. 206, 45-50.

Rojo, E.E., Guiard, B., Neupert, W. \& Stuart, R.A. (1999) N-terminal tail export from the mitochondrial matrix. Adherence to the prokaryotic "positive-inside" rule of membrane protein topology. J. Biol. Chem. 274, 1961719622.

Rosenthal, L.P. \& Bodley, J.W. (1987) Purification and characterization of Saccharomyces cerevisiae mitochondrial elongation factor Tu. J. Biol. Chem. 262, 10955-10959.

Sanchirico, M.E., Fox, T.D. \& Mason, T.L. (1998) Accumulation of mitochondrially synthesized Saccharomyces cerevisiae Cox $2 \mathrm{p}$ and Cox3p depends on targeting information in untranslated portions of their mRNAs. EMBO J. 17, 5796-5804.

Schneider, A., Behrens, M., Scherer, P., Pratje, E., Michaelis, G. \& Schatz, G. (1991) Inner membrane protease I, an enzyme mediating intramitochondrial protein sorting in yeast. $E M B O$ J. 10, 247-254.

Sevarino, K.A. \& Poyton, R.O. (1980) Mitochondrial membrane biogenesis: Identification of a precursor to yeast cytochrome $c$ oxidase subunit II, an integral polypeptide. Proc. Natl. Acad. Sci. U.S.A. 77, 142-146.
Snyers, L., Umlauf, E. \& Prohaska, R. (1998) Oligomeric nature of the integral membrane protein stomatin. J. Biol. Chem. 273, 1722117226.

Spithill, T.W., Trembath, M.K., Lukins, H.B. \& Linnane, A.W. (1978) Mutations of the mitochondrial DNA of Saccharomyces cerevisiae which affect the interaction between mitochondrial ribosomes and the inner mitochondrial membrane. Mol. Gen. Genet. 164, 155162.

Steele, D.F., Butler, C.A. \& Fox, T.D. (1996) Expression of a recoded nuclear gene inserted into yeast mitochondrial DNA is limited by mRNA-specific translational activation. Proc. Natl. Acad. Sci. U.S.A. 93, 5253-5257.

Steglich, G., Neupert, W. \& Langer, T. (1999) Prohibitins regulate membrane protein degradation by the m-AAA protease in mitochondria. Mol. Cell. Biol. 19, 3435-3442.

Suzuki, C.K., Rep, M., van Dijl, J.M., Suda, K., Grivell, L.A. \& Schatz, G. (1997) ATP-dependent proteases that also chaperone protein biogenesis. Trends Biochem. Sci. 22, 118-123.

Thorsness, P.E., White, K.H. \& Fox, T.D. (1993) Inactivation of YME1, a member of the ftsHSEC18-PAS1-CDC48 family of putative ATPase-encoding genes, causes increased escape of DNA from mitochondria in Saccharomyces cerevisiae. Mol. Cell. Biol. 13, $5418-5426$.

Tokatlidis, K. \& Schatz, G. (1999) Biogenesis of mitochondrial inner membrane proteins. $J$. Biol. Chem. 274, 35285-35288.

Torello, A.T., Overholtzer, M.H., Cameron, V.L., Bonnefoy, N. \& Fox, T.D. (1997) Deletion of the leader peptide of the mitochondrially encoded precursor of Saccharomyces cerevisiae cytochrome $c$ oxidase subunit II. Genetics 145, 903-910.

Tzagoloff, A., Nobrega, M., Gorman, N. \& Sinclair, P. (1993) On the functions of the yeast COX10 and COX11 gene products. Biochem. Mol. Biol. Int. 31, 593-598.

Vambutas, A., Ackerman, S.H. \& Tzagoloff, A. (1991) Mitochondrial translational-initiation 
and elongation factors in Saccharomyces cerevisiae. Eur. J. Biochem. 201, 643-652.

Wang, Z.G. \& Ackerman, S.H. (1998) Mutational studies with Atp12p, a protein required for assembly of the mitochondrial F1-ATPase in yeast. Identification of domains important for atp $12 \mathrm{p}$ function and oligomerization. J. Biol. Chem. 273, 2993-3002.

Wang, Z.G. \& Ackerman, S.H. (2000) The assembly factor Atp11p binds to the beta-subunit of the mitochondrial F(1)-ATPase. J. Biol. Chem. 275, 5767-5772.

Węgierski, T., Dmochowska, A., Jabłonowska, A., Dziembowski, A., Bartnik, E. \& Stępien, P.P. (1998) Yeast nuclear PET127 gene can suppress deletions of the SUV3 or DSS1 genes: An indication of a functional interaction between $3^{\prime}$ and $5^{\prime}$ ends of mitochondrial mRNAs. Acta Biochim. Polon. 45, 935-940.

Wiesenberger, G. \& Fox, T.D. (1997) Pet127, a membrane-associated protein involved in stability and processing of Saccharomyces cerevisiae mitochondrial RNAs. Mol. Cell. Biol. 17, 2816-2824.

Wiesenberger, G., Costanzo, M.C. \& Fox, T.D. (1995) Analysis of the Saccharomyces cerevisiae mitochondrial COX3 mRNA 5' untranslated leader: Translational activation and mRNA processing. Mol. Cell. Biol. 15, 32913300 .

Weiss-Brummer, B. \& Huttenhofer, A. (1989) The paromomycin resistance mutation (parr-454) in the $15 \mathrm{~S}$ rRNA gene of the yeast Saccharomyces cerevisiae is involved in ribosomal frameshifting. Mol. Gen. Genet. 217, 362-369.

Weiss, R.B., Murphy, J.P. \& Gallant, J.A. (1984) Genetic screen for cloned release factor genes. J. Bacteriol. 158, 362-364.

Wu, M. \& Tzagoloff, A. (1989) Identification and characterization of a new gene (CBP3) required for the expression of yeast coenzyme QH2-cytochrome $c$ reductase. J. Biol. Chem. 264, 11122-11130. 